Revista de

Contabilidade e

Organizações

www.rco.usp.br
DOI: http://dx.doi.org/10.11606/rco.v9i24.88647
Journal of

Accounting and

Organizations

www.rco.usp.br

\title{
Reputação corporativa negativa e o desempenho empresarial
}

Matheus Tanaques da Silva Souza Bandeira ; Alan Diógenes Góis ; Márcia Martins Mendes De Luca Alessandra Carvalho de Vasconcelos ${ }^{\mathrm{a}}$

a Universidade Federal do Ceará

${ }^{b}$ Universidade de São Paulo

\section{Informações do Artigo}

Histórico do Artigo

Recebido: 09 de dezembro de 2014

Aceito: 06 de agosto de 2015

Palavras chave:

Reputação Corporativa

Desempenho Empresarial

Visão Baseada em Recursos

\begin{abstract}
Resumo
Este estudo investiga a associação entre a reputação corporativa negativa e o desempenho, nas empresas listadas na BM\&FBovespa. Para a construção da reputação negativa, foram analisadas ações judiciais cíveis e trabalhistas consignadas nas notas explicativas às demonstrações contábeis, os dados do Sistema Nacional de Informações de Defesa do Consumidor, referentes ao triênio 2009-2011. Fez-se uso do banco de dados Economática ${ }^{\circledR}$ para determinar o desempenho empresarial. O estudo reúne 207 empresas, cujos dados foram submetidos à Análise de Correspondência. Os resultados mostraram que os setores Telecomunicação e Utilidade Pública possuem alta reputação corporativa negativa, e que as empresas com alta reputação negativa assinalam maior desempenho operacional, porém registram menor desempenho de mercado. Conclui-se que a reputação corporativa demonstra ser um recurso estratégico valioso, confirmando os pressupostos da Visão Baseada em Recursos, que surge a partir das expectativas sociais, e quando bem gerenciada tem a capacidade de gerar resultado superior e diferencial competitivo para as organizações.
\end{abstract}

Copyright (C) 2015 FEA-RP/USP. Todos os direitos reservados

\section{INTRODUÇÃO}

A globalização do mercado e os avanços tecnológicos vêm acirrando a competitividade entre organizações, forçando-as a se diferenciar, cada dia mais, de seus concorrentes. Nesse contexto, os recursos estratégicos, dentre eles os ativos intangíveis, geram condição para essa diferenciação, já que são bens escassos e difíceis de copiar (BARNEY, 1991). Além disso, os ganhos e os benefícios decorrentes do adequado gerenciamento desses ativos se refletem no desempenho empresarial, conforme defendem Carvalho, Kayo e Martin (2010).

Artoni (2008) destaca o aumento da utilidade dos ativos intangíveis como critério de diferenciação das empresas no mercado. Dentre os ativos intangíveis, a reputação corporativa ganha destaque nos meios acadêmico e empresarial, pois o adequado gerenciamento da reputação corporativa traz para a organização vantagem competitiva e outros benefícios, como, por exemplo, o desempenho superior (CAIXETA, 2008; MACÊDO et al., 2011).

Por essa abordagem, Roberts e Dowling (2002), Horiuchi (2010) e Thomaz e Brito (2010) destacam que a reputação corporativa é um dos ativos intangíveis responsáveis pelo desempenho sustentável apresentado nas firmas. Sob outro enfoque, Fombrun e Shanley (1990) revelam que os stakeholders são atraídos por empresas que possuem boa reputação corporativa, e isso ocorre devido às boas práticas mercadológicas por elas adotadas, como transparência, compromisso e qualidade dos produtos e/ou serviços (DOWLING, 1986).

Observa-se, portanto, que a reputação corporativa pode ser estudada sob duas abordagens: como um ativo e com base na relação avaliação-percepção (BARNETT; JERMIER; LAFFERTY, 2006). A partir dessas

Autor Correspondente: Tel (85) 33667802

E-mail: matheustanaques@gmail.com (M.T. S. S. Bandeira); alandgois@hotmail.com (A. D. Góis); marciadeluca@ufc.br (M.M. M. De Luca);

alevasconcelos.ufc@gmail.com (A. C. Vasconcelos)

Universidade Federal do Ceará, Faculdade de Economia Adm., Atuária, Contab. e Secretariado e Executivo - Av da universidade, 2431 - Benfica - 60020 -180 -

Fortaleza, CE - Brasil 
abordagens, pode-se afirmar que a reputação corporativa é conceituada sob os preceitos da Visão Baseada em Recursos (VBR) - ativo - e das expectativas sociais (dos stakeholders) - avaliação-percepção.

Dessa forma, o presente estudo considera a reputação corporativa um recurso estratégico, dependente das percepções de seus usuários, internos e externos, que cria valor para os acionistas, e cuja boa ou má percepção dos stakeholders impacta no desempenho empresarial (FOMBRUN; SHANLEY, 1990; CAIXETA, 2008; HORIUCHI, 2010; MONTARDO; CARVALHO, 2012). Essa perspectiva se embasa na VBR, na qual a reputação corporativa é caracterizada como ativo raro e valioso, que possibilita obter benefícios mercadológicos sobre seus concorrentes (BERGH et al., 2010).

$\mathrm{Na}$ abordagem avaliação-percepção, a reputação é representada pelo saldo de avaliações positivas e negativas, resultante das impressões vivenciadas pelos stakeholders, podendo, portanto, ser considerada uma reputação positiva ou uma reputação negativa. Ressalta-se, ainda, que a reputação pode ser entendida como um resultado decorrente de ações passadas e perspectivas futuras sobre o comportamento organizacional (GARDBERG; FOMBRUN, 2002).

Quanto à reputação corporativa negativa, Castro (2008) elenca alguns indícios que os stakeholders percebem para atribuição dessa reputação às empresas: processo produtivo com prejuízo para a sociedade, práticas antiéticas, produtos e serviços de baixa qualidade, monopólios, reclamações, influência política e falta de transparência.

Considerando-se que a boa reputação corporativa, ou reputação positiva, é uma das variáveis responsáveis por alavancar e sustentar o desempenho empresarial (FOMBRUN; SHANLEY, 1990; ROBERTS; DOWLING, 2002; CAIXETA, 2008; HORIUCHI, 2010; THOMAZ; BRITO, 2010; CAIXETA et al., 2011; CARDOSO et al., 2013), a reputação negativa pode gerar efeito inverso na empresa, ou seja, comprometer a sua lucratividade, devido às percepções negativas advindas principalmente de clientes e empregados, assim como da sociedade em geral.

Diante do exposto, o estudo busca resposta para o seguinte questionamento: Qual a relação entre a reputação corporativa negativa e o desempenho empresarial? Para tanto, elegeu-se como objetivo principal analisar a relação entre a reputação corporativa negativa e o desempenho das empresas brasileiras listadas na BM\&FBovespa. Como objetivo adicional, descreve-se o perfil das empresas com reputação negativa, segundo a origem e controle do capital e o seu setor econômico.

De natureza descritiva, com abordagem quantitativa, o estudo reúne uma população de 305 empresas listadas na BM\&FBovespa, que tiveram o valor de mercado, em 31/12/2012, registrado na base de dados Economática $^{\circledR}$. A amostra é composta por 207 empresas que durante o período de 2009 a 2011 apresentaram pelo menos um dos seguintes critérios utilizados na mensuração da reputação corporativa negativa desta pesquisa: reclamações junto ao Sistema Nacional de Informações de Defesa do Consumidor (Sindec), ações judiciais sobre questões trabalhistas e ações judiciais sobre questões cíveis. Detalhes sobre os fatores para a construção da reputação corporativa negativa e a variável desempenho empresarial utilizada, bem como sobre o tratamento estatístico dos dados, são apresentados em tópico específico deste estudo, referente aos procedimentos metodológicos.

Apesar de a reputação ser tema bastante discutido na atualidade, em várias áreas do conhecimento e no ambiente empresarial, ainda não se tem um conceito universal sobre a reputação corporativa (CARDOSO et al., 2013). Da mesma forma, o conceito de reputação corporativa negativa também não é consenso. Assim, a pesquisa se justifica na medida em que pretende contribuir para aumentar o conhecimento sobre a temática, associando a reputação corporativa negativa com o desempenho das empresas. Justifica-se, ainda, por procurar mensurar a reputação corporativa negativa a partir da construção de um ranking das empresas com maior reputação negativa. Destaca-se, também, o fato de ser ainda incipiente a literatura nacional que aborda os efeitos negativos da reputação corporativa no desempenho empresarial.

\section{REFERENCIAL TEÓRICO}

\subsection{Reputação corporativa e desempenho empresarial}

A reputação corporativa é tema de interesse de diversas áreas do conhecimento, como administração, marketing, estratégia, economia e contabilidade. Entretanto, não há um consenso universal sobre o seu conceito 
(FOMBRUN; GARDBERG; SEVER, 2000). Segundo Barnett, Jermier e Lafferty (2006), o estudo do conceito da reputação pode ser dividido em três tipos de abordagem: ativo, percepção e avaliação. No presente estudo, consideram-se as abordagens percepção e avaliação como uma só (percepção-avaliação). Assim, a primeira (ativo) caracteriza a reputação como um ativo intangível das organizações; por sua vez, a segunda (percepçãoavaliação) aduz que a reputação se constitui a partir da percepção dos stakeholders, mais especificamente dos clientes das organizações, tornando-se um produto da avaliação moral dos stakeholders (BARNETT; JERMIER; LAFFERTY, 2006). A partir dessas abordagens, pode-se afirmar que a reputação é conceituada sob os preceitos da VBR e das expectativas sociais (dos stakeholders).

Quanto à VBR, em um cenário econômico globalizado, as organizações estão cada dia mais considerando a reputação empresarial um importante recurso estratégico para permanecerem no mercado (ALMEIDA, 2005). Horiuchi (2010) ressalva a necessidade de gerenciar esse recurso, de modo a criar valor para os acionistas e desfrutar dos benefícios decorrentes da boa reputação corporativa projetada.

Nessa conjectura, Castro (2008) assevera que a reputação corporativa é uma fonte de vantagem competitiva e fator relevante na criação de valor para os acionistas. Dessa forma, a reputação é vista como um ativo precioso para a firma. Tal conceito é empregado pela VBR, a qual afirma que a organização possui ativos raros, específicos e não copiáveis (dentre os quais a reputação), responsáveis por alcançar retornos superiores, ao transferir seus benefícios para os produtos e serviços (ROBERTS; DOWLING, 2002; MACÊDO et al., 2011).

Como recurso estratégico, Artoni (2008) e Cardoso et al. (2013) consideram a reputação corporativa um bem intangível de alto valor para as firmas, em virtude de seu relacionamento com os stakeholders, em que o desempenho financeiro depende do grau de influência que a reputação exerce sobre eles. Assim, uma alteração desse relacionamento pode interferir na performance empresarial. Dessa forma, uma reputação desfavorável pode limitar o desempenho futuro da organização, em virtude da diminuição da competitividade, fundamental fator de sobrevivência em um ambiente econômico de competição acirrada.

Quanto às expectativas sociais, Castro (2008) considera a reputação corporativa fruto do julgamento dos stakeholders, de modo que a atratividade da firma é fator preponderante na criação da reputação, pelo fato de ser concebida através das interações ocorridas ao longo do tempo entre os grupos de interesse e a organização. Artoni (2008) utiliza as expectativas sociais como instrumento formador da reputação. Entende-se, portanto, que o construto reputação organizacional é avaliado pelo atendimento das necessidades de cada stakeholder, e o resultado pode ser a construção de uma boa ou de uma má reputação (THOMAZ; BRITO, 2010). Desse modo, as experiências negativas acumuladas pelos stakeholders relativas à firma podem gerar uma reputação negativa, e, consequentemente, afetar o fluxo de caixa futuro.

Almeida (2005) sugere que por estarem cada dia mais sendo pressionadas pelos grupos de interesse, as empresas devem buscar maior comprometimento sobre questões sociais e procurar aprimorar ações e projetos sustentáveis. Assim, Caixeta (2008) assevera que o sucesso empresarial deriva de resultados econômicos persistentes e do cumprimento das responsabilidades sociais almejadas pelos seus públicos interno e externo. Diante disso, e dadas as evidências empíricas que corroboram a ideia de associação da reputação corporativa sobre o desempenho econômico e financeiro (ROBERTS; DOWLING, 2002; ARTONI, 2008; HORIUCHI, 2010; THOMAS; BRITO, 2010), as empresas precisam gerenciar e manter boa imagem organizacional diante dos grupos nelas interessados (CARDOSO et al., 2013).

Dessa forma, Montardo e Carvalho (2012, p. 169) argumentam que "a reputação é um atributo da confiança a partir da performance corporativa associada a um bom nome, familiaridade, goodwill, credibilidade e reconhecimento; é fruto do histórico de relacionamentos". Por ser um recurso não totalmente controlado pelos administradores, leva tempo para os stakeholders construírem boa imagem sobre a organização e, por sua vez, a reputação (CAIXETA et al., 2011).

Em síntese, observa-se que o construto reputação corporativa é desenvolvido sob duas perspectivas teóricas: VBR e expectativas sociais. A primeira afirma que a reputação corporativa deve ser caracterizada como ativo raro e valioso, que possibilita obter benefícios mercadológicos sobre seus concorrentes. Nesse sentido, a reputação possibilita que a empresa venha a praticar preços premium, reter e barganhar melhores funcionários, fidelizar clientes, obter investimento a custo menor, em razão da credibilidade, e ter riscos inferiores (FOMBRUN; SHANLEY, 1990), além de criar barreiras protecionistas, dificultando a entrada e/ou articulações de outras empresas (CAIXETA, 2008).

A outra perspectiva teórica - expectativas sociais - propõe que a reputação é o resultado do relacionamento construído ao longo do tempo entre a empresa e os diversos públicos de interesse. Por essa razão é que a gestão eficiente da reputação deve ser capaz de monitorar os atributos de maior relevância para cada grupo de interesse, 
no momento de avaliar o comportamento e as ações da firma, já que cada stakeholder carrega suas próprias crenças, valores e expectativas (ALMEIDA, 2005). Ainda, segundo a autora, a construção da reputação é obtida quando a organização detecta tais atributos e quando consegue alinhar a imagem da corporação aos valores dos stakeholders (VANCE; ÂNGELO, 2007).

Portanto, para o presente estudo, a reputação corporativa é considerada um recurso estratégico, dependente das percepções de seus usuários internos e externos, que cria valor para seus acionistas, em que a boa ou má percepção dos stakeholders impacta no desempenho empresarial (FOMBRUN; SHANLEY, 1990; CAIXETA, 2008; HORIUCHI, 2010; MONTARDO; CARVALHO, 2012).

\subsection{Estudos empíricos anteriores}

Levando-se em conta os escassos estudos sobre a influência da má reputação corporativa ou reputação corporativa negativa no desempenho empresarial, propõe-se levantar os achados que relacionem a boa reputação com o desempenho empresarial e inferir sobre o inverso dessa relação.

Roberts e Dowling (2002) investigaram o impacto da reputação corporativa no desempenho organizacional das empresas participantes do ranking America's Most Admired Corporations, da revista Fortune. Os resultados apontaram uma correlação positiva entre a reputação corporativa e o desempenho persistente.

Brito (2005) avaliou a relação entre a reputação corporativa, a percepção da imagem e o desempenho econômico das agências de um dos maiores bancos brasileiros. Os achados, no entanto, foram de baixa correlação entre a percepção da imagem e da reputação das agências pelos clientes e o respectivo desempenho econômico. Com relação ao posicionamento dos funcionários, à reputação e à imagem de suas agências, foi possível explicar $70 \%$ do desempenho financeiro das agências.

Artoni (2008) verificou se as empresas com reputação corporativa mais bem avaliada, segundo "As empresas mais admiradas do Brasil", registram melhor desempenho econômico-financeiro. Os resultados mostraram que a hipótese é verdadeira, ou seja, a reputação influencia positivamente o desempenho organizacional.

Caixeta (2008) analisou três dimensões da metodologia RepTrak (governança, desempenho e produtos e serviços) de reputação e sua relação com o resultado econômico de cinco conglomerados brasileiros (Petrobras, Vale, Votorantim, Pão de Açúcar e Embraer). Os resultados não mostraram existir estatisticamente uma relação direta entre desempenho econômico-financeiro e reputação corporativa.

Horiuchi (2010) testou empiricamente a relação entre reputação corporativa e valor de mercado das companhias negociadas no mercado acionário brasileiro. Os dados analisados, referentes aos anos de 2002 a 2005, apresentaram relações estatisticamente significantes entre a pontuação das empresas no ranking setorial de “As empresas mais admiradas do Brasil" e seu Market-to-Book ratio (relação entre valor de mercado e patrimônio líquido contábil), sugerindo que as empresas com melhor reputação corporativa obtêm maior avaliação pelo mercado de ações.

Com o objetivo de testar a relação entre reputação, identificação, comunicação e desempenho organizacional, de dois principais grupos de interesse na empresa, no caso funcionários e clientes, Thomaz e Brito (2010) encontraram uma associação positiva entre reputação e desempenho financeiro no conjunto de 57 empresas analisadas.

Cardoso et al. (2013) investigaram a relação entre a reputação corporativa e o desempenho empresarial, segundo a classificação do Reputation Institute. Com um rol de 84 empresas de capital aberto classificadas pelo órgão, os achados mostraram que as firmas com boa reputação corporativa apresentaram resultados superiores aos das demais.

Domingos e Moura (2013) analisaram a associação entre a reputação corporativa e o desempenho das maiores companhias abertas do Brasil. Os resultados demonstraram que não se pode afirmar que há uma associação entre a reputação corporativa e o desempenho.

Hall Jr. e Lee (2014) verificaram a relação entre a reputação corporativa e o desempenho empresarial no contexto estadunidense e japonês. Considerando três variáveis de desempenho operacional - retorno sobre o ativo, retorno sobre o patrimônio líquido e retorno sobre as vendas - e uma variável de desempenho de mercado, Q de Tobin, os autores encontram uma relação positiva entre a reputação corporativa e o desempenho empresarial operacional e de mercado em ambos os contextos. 
Kakkar e Kaur (2014) examinaram a relação entre a reputação corporativa e o desempenho financeiro das empresas indianas. Os resultados mostram um impacto positivo e significativo da reputação com desempenho, além do que a reputação do ano tem impacto positivo sobre o desempenho financeiro do ano seguinte. Os autores ainda observaram que a reputação corporativa é incorporada nos preços das ações das empresas, considerando uma janela de longo prazo.

Como não foram encontrados estudos que correlacionam a reputação corporativa negativa com o desempenho empresarial, assumiu-se de maneira análoga à associação existente entre a boa reputação e o desempenho, que a construção de uma reputação organizacional negativa pode interferir no desempenho econômico das organizações, produzindo resultados indesejáveis para os acionistas. Sob essa perspectiva, cabe destacar ainda, a afirmação de Barnett e Pollock (2012) de que a má reputação é fácil de ser adquirida e difícil de ser removida, e que a percepção dessa reputação é mais indicativa para a sociedade do que a boa reputação.

\section{PROCEDIMENTOS METODOLÓGICOS}

Quanto aos objetivos, a pesquisa se classifica como descritiva, já que adota um grupo de informações e as descreve, buscando características e associações entre elas (COLLIS; HUSSEY, 2005). Quanto à natureza, trata-se de pesquisa quantitativa, haja vista que procura investigar associações entre variáveis por meio de algum modelo estatístico, para análise e interpretação dos resultados (SAMPIERI; COLLADO; LÚCIO, 2013). Quanto aos procedimentos, caracteriza-se por ser documental, por usar materiais não editados (MARTINS; THEÓPHILO, 2009).

A população do estudo compreende todas as companhias listadas na BM\&FBovespa que tiveram em 31/12/2012 o valor de mercado registrado na base de dados Economática ${ }^{\circledR}$, totalizando 305 empresas. Por sua vez, a amostra reúne 207 empresas que durante o período de 2009 a 2011 apresentaram pelo menos um dos seguintes fatores utilizados na mensuração da reputação corporativa negativa deste estudo: reclamações junto ao Sindec, ações judiciais sobre questões trabalhistas e ações judiciais sobre questões cíveis.

Para a construção do ranking reputação corporativa negativa, foram utilizados três fatores, considerados de percepção negativa pela sociedade: (i) número de reclamações junto ao Sindec, cujos dados foram obtidos no seu portal eletrônico; (ii) montante das ações judiciais trabalhistas, provisionadas como prováveis, dividido pelo Passivo total; e (iii) montante das ações judiciais cíveis, provisionadas como prováveis, dividido pelo Passivo total. Os dados referentes às ações judiciais foram obtidos a partir da análise de conteúdo das notas explicativas às demonstrações financeiras das empresas, disponíveis no portal eletrônico da BM\&FBovespa. O Sindec permite o registro dos atendimentos individuais a consumidores, a instrução dos procedimentos de atendimento e dos processos de reclamação, além da gestão das políticas de atendimento e fluxos internos dos Programas de Proteção e Defesa do Consumidor (PROCONs), integrados, e a elaboração de Cadastros Estaduais e Nacional de Reclamações Fundamentais.

De forma similar ao que é adotado pelo Monitor Empresarial de Reputación Corporativa (MERCO, 2014), para elaboração dos seus rankings, no presente estudo, cada um dos fatores da reputação corporativa negativa pode alcançar até 10.000 pontos. O primeiro fator, representado pelo número de reclamações junto ao Sindec, é obtido da seguinte forma: para a empresa que apresentou o maior número de reclamações, foram atribuídos 10.000 pontos, enquanto para as demais, utilizou-se a regra de três simples para se atribuir as respectivas pontuações, levando-se em conta a primeira. O segundo fator - montante das ações judiciais trabalhistas divulgadas nas notas explicativas, dividido pelo Passivo total da empresa - foi calculado de forma semelhante: para a empresa que evidenciou a maior razão entre o montante de ações judiciais trabalhistas e o Passivo total, foram atribuídos 10.000 pontos, utilizando-se também da regra de três simples para se atribuir os pontos das demais empresas. Da mesma forma, o terceiro fator: o montante das ações judiciais cíveis divulgadas nas notas explicativas, dividido pelo Passivo total. Foram, então, atribuídos 10.000 pontos para a empresa que revelou a maior razão entre o montante de ações judiciais cíveis e o seu Passivo total, adotando-se procedimento similar aos anteriores para pontuação das demais empresas.

Por meio desses fatores, a reputação negativa da empresa é a média do somatório das pontuações de cada fator no triênio 2009-2011, e as empresas foram organizadas em ordem decrescente dos montantes de pontos obtidos, de forma a se formar o ranking da reputação corporativa negativa.

Utilizou-se a defasagem temporal para analisar a relação entre a reputação e o desempenho, pois, de 
acordo com Roberts e Dowling (2002), a reputação é um atributo que se constrói ao longo do tempo, e os seus impactos são observados em períodos subsequentes. Dessa forma, para os fins deste estudo, entende-se que os reflexos da reputação corporativa negativa no desempenho das empresas somente são verificados no futuro. Para tanto, os fatores para a composição da reputação negativa, descritos adiante, referem-se aos exercícios de 2009 a 2011, enquanto o desempenho empresarial diz respeito ao exercício de 2012.

O desempenho empresarial foi analisado sob duas perspectivas: operacional e de mercado. No estudo, o desempenho empresarial operacional é mensurado pelo Return On Equity (ROE), enquanto o desempenho empresarial de mercado é mensurado pelo Market Value Added (MVA). Assaf Neto (1997) assevera que o ROE permite ao investidor observar o valor de retorno e verificar a gestão dos recursos próprios e de terceiros. Para Young e O’Byrne (2003), o MVA se baseia no comportamento ou percepção do mercado, além do que demonstra o quanto a administração agrega valor ao capital investido na companhia no longo prazo (BASSO; KRAUTER, 2003; CERQUEIRA; SOARES; DAVID, 2009).

Com base na literatura apresentada, em que se demonstra a relação entre reputação corporativa e desempenho empresarial, tem-se as seguintes hipóteses de pesquisa.

$\mathrm{H}_{1 \mathrm{a}}$ : A reputação corporativa negativa tem relação inversa com o desempenho empresarial operacional.

$\mathrm{H}_{1 \mathrm{~b}}$ : A reputação corporativa negativa tem relação inversa com o desempenho empresarial de mercado.

Para testar tais hipóteses, aplica-se a Regressão Linear Múltipla. Assim, o estudo envolve dois modelos, em que o primeiro, representado pela Equação 1, demonstra o desempenho operacional, e o segundo modelo, representado pela Equação 2, mostra o desempenho de mercado.

$$
\begin{array}{ll}
\operatorname{ROE}_{\mathrm{i}}=\beta_{0}+\beta_{1} \mathrm{REP}_{\mathrm{i}}+\beta_{2} \mathrm{TAM}_{\mathrm{i}}+\beta_{3} \mathrm{END}_{\mathrm{i}}+\beta_{4} \mathrm{IDA}_{\mathrm{i}}+\beta_{5} \mathrm{SET}_{\mathrm{i}}+\varepsilon & \text { (Equação 1) } \\
\mathrm{MVA}_{\mathrm{i}}=\beta_{0}+\beta_{1} \mathrm{REP}_{\mathrm{i}}+\beta_{2} \mathrm{TAM}_{\mathrm{i}}+\beta_{3} \mathrm{END}_{\mathrm{i}}+\beta_{4} \mathrm{IDA}_{\mathrm{i}}+\beta_{5} \mathrm{SET}_{\mathrm{i}}+\varepsilon & \text { (Equação 2) }
\end{array}
$$

O Quadro 1 apresenta um resumo dos dados utilizados para atender aos objetivos do estudo, sua

\begin{tabular}{|c|c|c|c|}
\hline \multicolumn{2}{|l|}{ Variável } & Operacionalização & Fonte de coleta \\
\hline Return On Equity & ROE & Lucro Líquido / Patrimônio Líquido & Economática $^{\circledR}$ \\
\hline $\begin{array}{l}\text { Market Value } \\
\text { Added }\end{array}$ & MVA & $\begin{array}{l}\text { (Valor de Mercado - Patrimônio Líquido) / Patrimônio } \\
\text { Líquido }\end{array}$ & Economática $^{\circledR}$ \\
\hline $\begin{array}{l}\text { Reputação } \\
\text { Corporativa } \\
\text { Negativa }\end{array}$ & REP & $\begin{array}{l}\text { Média do somatório das pontuações de cada fator no } \\
\text { triênio 2009-2011. } \\
\text { O primeiro fator é o número de reclamações junto ao } \\
\text { Sindec; o segundo fator é o montante das ações judiciais } \\
\text { trabalhistas, dividido pelo Passivo total; e o terceiro fator } \\
\text { é o montante das ações judiciais cíveis, dividido pelo } \\
\text { Passivo total. } \\
\text { Para a empresa que possui o maior valor em algum fator } \\
\text { foram atribuídos } 10.000 \text { pontos, sendo que para as demais, } \\
\text { foi aplicada uma regra de três simples. }\end{array}$ & $\begin{array}{c}\text { Base de } \\
\text { reclamações do } \\
\text { Sindec, Notas } \\
\text { Explicativas e } \\
\text { Economática }^{\circledR}\end{array}$ \\
\hline Tamanho & TAM & Logaritmo natural do Ativo Total & Economática $^{\circledR}$ \\
\hline Endividamento & END & Passivo Total / Patrimônio Líquido & Economática $^{\circledR}$ \\
\hline Idade & IDA & Diferença entre o ano de constituição e o ano 2012. & $\begin{array}{l}\text { Formulário } \\
\text { Cadastral }\end{array}$ \\
\hline Setor Serviço & SER & $\begin{array}{l}\text { Variável dummy, sendo atribuído } 1 \text { para empresas do setor } \\
\text { de serviço e } 0 \text { caso contrário. }\end{array}$ & $\begin{array}{l}\text { Formulário } \\
\text { Cadastral }\end{array}$ \\
\hline
\end{tabular}
operacionalização e fonte de coleta.

Quadro 1. Resumo dos dados utilizados na pesquisa

Fonte: Elaborado pelos autores.

Para atender o objetivo adicional, foram utilizadas informações apresentadas no Formulário Cadastral, referentes a origem e controle de capital das empresas, assim como o seu setor econômico. Destarte, para apresentar o perfil das empresas, primeiramente se utilizou da tabela de contingência que relaciona origem e controle de capital com o setor econômico, e por fim, desenvolveu-se dois rankings, evidenciando as dez empresas com maior reputação negativa e as dez empresas com menor reputação negativa. O tratamento dos dados, por meio da Regressão Linear Múltipla, foi realizado com o auxílio do aplicativo STATA, versão 13. 


\section{ANÁLISE DOS RESULTADOS}

\subsection{Perfil e descrição da amostra}

O presente tópico se destina à análise e à interpretação dos resultados obtidos pela pesquisa. Primeiramente, foi observada a composição da amostra e realizada a análise descritiva dos dados, a fim de se entender suas características. A Tabela 1 apresenta a distribuição da amostra por setor econômico, conforme classificação da BM\&FBovespa, assim como a origem do capital e o controle acionário.

Tabela 1. Perfil da amostra por setor econômico, origem e controle do capital

\begin{tabular}{l|c|c|c|c}
\hline \multirow{2}{*}{ Setor econômico } & \multicolumn{4}{|c}{ Origem e Controle do Capital } \\
\cline { 2 - 5 } & Nacional-Privado & Nacional-Estatal & Estrangeiro-Privado & Total \\
\hline Bens Industriais & 18 & 0 & 0 & $\mathbf{1 8}$ \\
\hline $\begin{array}{l}\text { Construção e } \\
\text { Transporte }\end{array}$ & 26 & 0 & 4 & $\mathbf{3 0}$ \\
\hline Consumo Cíclico & 34 & 0 & 4 & $\mathbf{3 7}$ \\
\hline $\begin{array}{l}\text { Consumo Não } \\
\text { Cíclico }\end{array}$ & 20 & 0 & 4 & $\mathbf{2 4}$ \\
\hline Financeiro e Outros & 26 & 5 & 1 & $\mathbf{3 5}$ \\
\hline Materiais Básicos & 20 & 0 & 0 & $\mathbf{2 1}$ \\
\hline $\begin{array}{l}\text { Petróleo, Gás e } \\
\text { Biocombustíveis }\end{array}$ & 1 & 1 & 0 & $\mathbf{2}$ \\
\hline $\begin{array}{l}\text { Tecnologia da } \\
\text { Informação }\end{array}$ & 5 & 1 & 0 & $\mathbf{6}$ \\
\hline Telecomunicações & 4 & 10 & 1 & $\mathbf{4}$ \\
\hline Utilidade Pública & 19 & $\mathbf{1 7}$ & $\mathbf{1 7}$ & $\mathbf{2 0 7}$ \\
\hline Total & $\mathbf{1 7 3}$ & 0 & 4 \\
\hline
\end{tabular}

Fonte: Dados da pesquisa.

Constata-se que o setor Consumo Cíclico é aquele que reúne maior número de empresas da amostra, com cerca de 18\%, seguido pelos setores Financeiro e Outros, com 17\%, Construção e Transporte, com 14,5\%, e Utilidade Pública, com 14,5\%. Nota-se que os setores Petróleo, Gás e Biocombustíveis, Tecnologia da Informação e Telecomunicações, somados, correspondem a apenas 6\% da amostra. Quanto à origem do capital e ao controle acionário, em sua maioria as empresas possuem capital de origem nacional e controle privado, ambos próximos de $92 \%$ do total da amostra.

Retoma-se que o ranking da reputação corporativa negativa, elaborado neste estudo, é composto pelo montante de ações judiciais trabalhistas e cíveis, provisionadas como prováveis, constante nas notas explicativas às demonstrações financeiras das empresas, e pela quantidade de reclamações registradas junto ao Sindec. As ações judiciais trabalhistas compõem, geralmente, processo relativo ao pagamento de horas extras e noturnas, verbas rescisórias, adicionais salariais e verbas em razão de responsabilidade subsidiária, enquanto as ações judiciais cíveis são bastante específicas para cada empresa, representando, de modo geral, processos de indenização, rescisão de cláusulas de contratos, reparação de danos, entre outros. As reclamações junto ao Sindec são sobre produtos danificados, cobrança indevida e/ou abusiva, não entrega de produtos, descumprimento de garantias, falhas bancárias, danos materiais decorrentes de serviços mal prestados, dentre outros.

O ranking da reputação negativa das empresas é composto de 207 posições, dentre as quais o presente estudo destaca as dez empresas com maior reputação corporativa negativa e as dez empresas com menor reputação corporativa negativa, conforme as Tabelas 2 e 3 , respectivamente. 
Tabela 2. As dez empresas com maior reputação corporativa negativa

\begin{tabular}{|c|c|c|c|c|c|c|c|c|}
\hline \multirow[b]{2}{*}{ Nome } & \multirow[b]{2}{*}{ Reputação } & \multicolumn{4}{|c|}{ Período/Classificação } & \multirow{2}{*}{$\begin{array}{c}\text { Setor } \\
\text { Econômico }\end{array}$} & \multicolumn{2}{|c|}{ Capital } \\
\hline & & $\begin{array}{l}2011- \\
2009\end{array}$ & 2011 & 2010 & 2009 & & Origem & Natureza \\
\hline Metisa & $3.682,39$ & 1 & 1 & 1 & 7 & Bens Industriais & Nacional & Privado \\
\hline Grazziotin & $3.317,45$ & 2 & 4 & 3 & 6 & Consumo Cíclico & Nacional & Privado \\
\hline Whirlpool & $3.158,83$ & 3 & 8 & 2 & 2 & Consumo Cíclico & Estrangeiro & Privado \\
\hline Telebras & $2.625,75$ & 4 & 13 & 6 & 1 & $\begin{array}{l}\text { Tecnologia da } \\
\text { Informação }\end{array}$ & Nacional & Estatal \\
\hline Oi & $1.919,45$ & 5 & 11 & 5 & 13 & Telecomunicações & Nacional & Privado \\
\hline $\begin{array}{c}\text { B2W } \\
\text { Digital }\end{array}$ & $1.756,52$ & 6 & 2 & 10 & 25 & Consumo Cíclico & Nacional & Privado \\
\hline Celpa & $1.503,87$ & 7 & 15 & 12 & 5 & Utilidade Pública & Nacional & Privado \\
\hline Pettenati & $1.468,01$ & 8 & 3 & 9 & 192 & Consumo Cíclico & Nacional & Privado \\
\hline Bradesco & $1.414,71$ & 9 & 6 & 8 & 15 & $\begin{array}{c}\text { Financeiro e } \\
\text { Outros }\end{array}$ & Nacional & Privado \\
\hline Pine & $1.404,40$ & 10 & 26 & 7 & 11 & $\begin{array}{c}\text { Financeiro e } \\
\text { Outros }\end{array}$ & Nacional & Privado \\
\hline
\end{tabular}

Fonte: Dados da pesquisa.

Percebe-se que a maioria das empresas permaneceu em média em suas relativas posições ao longo dos três anos analisados, salvo a Pettenati, que passou da classificação 192ª em 2009 para a 3 ${ }^{\mathrm{a}}$ em 2011, sugerindo piora na reputação corporativa. Destaca-se que a Celpa, a Telebras e o banco Pine foram as empresas que passaram para uma melhor condição nos anos em análise: a Celpa passou de $5^{\mathrm{a}}$ em 2009 para 15 em 2011; a Telebras passou de $1^{\mathrm{a}}$ em 2009 para 13 $3^{\mathrm{a}}$ em 2011; e o banco Pine passou de $11^{\mathrm{a}}$ em 2009 para $26^{\mathrm{a}} \mathrm{em} \mathrm{2011.} \mathrm{Em}$ relação aos setores econômicos das empresas do ranking das dez empresas, verificou-se que dentre aquelas com maior reputação corporativa negativa, quatro são do setor Consumo Cíclico. Já quanto à origem do capital e ao controle acionário, prevaleceram a origem nacional e o controle privado, devido ao fato de estes corresponderem a $92 \%$ da amostra, conforme já apresentado na Tabela 1.

Tabela 3. As dez empresas com menor reputação corporativa negativa

\begin{tabular}{c|c|c|c|c|c|c|c|c}
\hline \multirow{2}{*}{ Nome } & \multirow{2}{*}{ Reputação } & \multicolumn{3}{|c|}{ Período/Classificação } & \multicolumn{2}{c}{$\begin{array}{c}\text { Setor } \\
\text { Econômico }\end{array}$} & Origem & Natureza \\
\cline { 3 - 6 } & $\mathbf{2 0 1 1 -}$ & $\mathbf{2 0 1 1}$ & $\mathbf{2 0 1 0}$ & $\mathbf{2 0 0 9}$ & & \multicolumn{2}{c}{ Capital } \\
\hline Cetip & 0,00 & 207 & 199 & 200 & 203 & Financeiro & Nacional & Privado \\
\hline Tex Renaux & 0,01 & 206 & 197 & 198 & 202 & $\begin{array}{c}\text { Consumo Não } \\
\text { Cíclico }\end{array}$ & Nacional & Privado \\
\hline $\begin{array}{c}\text { BR } \\
\text { Insurance }\end{array}$ & 0,01 & 205 & 195 & 206 & 207 & Financeiro e Outros & Nacional & Privado \\
\hline Vale & 0,06 & 204 & 198 & 197 & 190 & Materiais Básicos & Nacional & Privado \\
\hline $\begin{array}{c}\text { Petrobras } \\
\text { Taesa }\end{array}$ & 0,09 & 203 & 201 & 201 & 187 & $\begin{array}{c}\text { Petróleo. Gás e } \\
\text { Biocombustíveis }\end{array}$ & Nacional & Estatal \\
\hline Panatlantica & 0,12 & 201 & 186 & 186 & 201 & Materiais Básicos & Nacional & Privado \\
\hline $\begin{array}{c}\text { SLC } \\
\text { Agricola }\end{array}$ & 0,14 & 200 & 190 & 196 & 188 & $\begin{array}{c}\text { Consumo Não } \\
\text { Cíclico }\end{array}$ & Nacional & Privado \\
\hline Brasmotor & 0,16 & 199 & 191 & 195 & 186 & Consumo Cíclico & Estrangeiro & Privado \\
\hline BR Propert & 0,19 & 198 & 178 & 184 & 200 & Financeiro e Outros & Nacional & Privado \\
\hline
\end{tabular}

Fonte: Dados da pesquisa.

Como apresentado na Tabela 2, as empresas praticamente permaneceram em suas posições ao longo do tempo. Observa-se na Tabela 3 que, dentre as dez empresas com menor reputação corporativa negativa, não há 
predominância de setor. Já a origem e o controle do capital se mantiveram como apresentado nas Tabelas 1 e 2 , ou seja, com predominância de empresas que possuem capital de origem nacional e controle privado.

4.2. Relação da reputação corporativa negativa com o desempenho empresarial

Antes de proceder à Regressão Linear Múltipla, que visa atender ao objetivo principal, realizou-se uma análise da estatística descritiva das variáveis utilizadas na pesquisa, sendo excluída a variável setor econômico, por se tratar de variável dummy. Destarte, a Tabela 4 apresenta o resultado da estatística descritiva dos dados.

Tabela 4. Estatística descritiva

\begin{tabular}{c|c|c|c|c|c}
\hline Variável & Mínimo & Máximo & Média & $\begin{array}{c}\text { Desvio } \\
\text { padrão }\end{array}$ & $\begin{array}{c}\text { Coeficiente de } \\
\text { variação }\end{array}$ \\
\hline MVA & $-23,75$ & 56,13 & 1,43 & 6,41 & 4,48 \\
\hline ROE & $-56,11$ & 13,98 & $-0,14$ & 4,07 & $-29,75$ \\
\hline REP & 0,00 & 3682,39 & 165,70 & 487,80 & 2,94 \\
\hline TAM & 8,78 & 20,85 & 15,02 & 1,90 & 0,13 \\
\hline END & $-51,09$ & 249,58 & 3,26 & 18,33 & 5,63 \\
\hline IDA & 2 & 257 & 43 & 33 & 0,78 \\
\hline
\end{tabular}

Fonte: Dados da pesquisa.

Por meio do coeficiente de variação, observa-se que todas as variáveis apresentam alta dispersão, com exceção do tamanho (TAM), podendo-se afirmar que a reputação corporativa (REP), o desempenho empresarial (ROE e MVA), o endividamento (END) e a idade (IDA) das 207 empresas da amostra apresentam comportamento bastante heterogêneo. Esse resultado é refletido ainda, quando se observa a reputação corporativa (REP), em que a média das empresas é de 165,70 pontos, enquanto a contagem máxima é de 3.682,39 pontos e a mínima é de aproximadamente zero ponto. Relação semelhante é observada quanto ao desempenho empresarial, já que o MVA registra uma média de 1,43, enquanto o valor máximo é de 56,13, e o mínimo é, negativo, de $23,75$. Já o ROE registra uma média de - 0,14, enquanto o valor máximo é de 13,98, e o mínimo é de - 56,11. Em média, as empresas possuem um endividamento de 3,26, e possuem uma idade de 43 anos. Quanto ao tamanho, utilizando-se da função exponencial, observa-se que as empresas, em média, possuem um ativo total de R\$ 3.339.692.300,57.

Uma vez apresentada a análise descritiva dos dados, passou-se à análise das relações entre as variáveis do estudo, utilizando-se a Correlação de Pearson, cujos resultados são demonstrados na Tabela 5.

Tabela 5. Correlação de Pearson

\begin{tabular}{c|c|c|c|c|c|c|c}
\hline & MVA & ROE & REP & TAM & END & IDA & SER \\
\hline MVA & 1 & & & & & & \\
\hline ROE & $-0,6173^{* * *}$ & 1 & & & & & \\
\hline REP & $-0,058$ & $-0,0106$ & 1 & & & & \\
\hline TAM & $-0,0097$ & 0,0283 & 0,0238 & 1 & & & \\
\hline END & $0,6801^{* * *}$ & $-0,9672^{* * *}$ & 0,0053 & 0,0548 & 1 & & \\
\hline IDA & $-0,0577$ & $-0,0095$ & 0,0561 & $-0,1063$ & 0,0262 & 1 & \\
\hline SER & $-0,1088$ & 0,0704 & 0,0194 & $0,3601^{* * *}$ & $-0,0064$ & $-0,1258^{*}$ & 1 \\
\hline
\end{tabular}

Nota: (*) Significância de até 10\%; Significância de até 1\% (***)

Fonte: Dados da pesquisa.

A partir da Tabela 5, percebe-se apenas cinco relações, sendo apenas uma de significância de até 10\%, as demais relações possuem significância de até 1\%. A primeira relação se apresenta entre as variáveis dependentes do estudo (ROE e MVA), no qual há relação inversa, sugerindo que quanto maior o desempenho de mercado (MVA), menor o desempenho operacional (ROE). Outras duas relações são observadas entre o endividamento e 
as variáveis dependentes, verificando-se uma relação positiva entre o endividamento e o desempenho de mercado e uma relação negativa entre o endividamento e o desempenho operacional. Por fim, as duas últimas relações são entre o setor serviço (SER) e o tamanho (TAM) e ainda, entre o setor serviços (SER) e a idade (IDA), sendo uma relação positiva e outra negativa, respectivamente.

Após a realização da estatística descritiva e da Correlação de Pearson, realizou-se a Regressão Linear Múltipla, com a finalidade de testar as hipóteses do estudo. A Tabela 6 apresenta os resultados da regressão para a amostra de 207 empresas.

Tabela 6. Regressão Linear Múltipla

\begin{tabular}{c|c|c}
\hline \multirow{2}{*}{ Variável } & ROE & MVA \\
\cline { 2 - 3 } & Coeficiente & Coeficiente \\
\hline REP & $-0,000$ & $-0,001 * *$ \\
\hline TAM & $0,148^{* * *}$ & $-0,054$ \\
\hline END & $-0,216^{* * *}$ & $0,239 * * *$ \\
\hline IDA & $0,003 * *$ & $-0,017$ \\
\hline SET & $0,360 * * *$ & $-1,428^{* *}$ \\
\hline Constante & $-1,938^{* * *}$ & 2,854 \\
\hline $\mathrm{R}^{2}$ & 0,944 & 0,485 \\
\hline Teste $\mathrm{F}$ & $89,82 * * *$ & $26,56 * * *$ \\
\hline
\end{tabular}

Nota: (**) Significância de até 5\%; Significância de até 1\% (***)

Fonte: Dados da pesquisa.

Considerando o primeiro modelo, que possui como variável dependente o desempenho operacional (ROE), nota-se uma significância de até $1 \%$ e um $\mathrm{R}^{2}$ de $94,4 \%$. A reputação corporativa negativa (REP) apresentou uma relação negativa com o ROE, contudo, tal relação foi não significante, logo, a reputação corporativa negativa não é um fator que influencia o desempenho empresarial quando considerada a amostra analisada. As variáveis de controle apresentaram uma relação significante com o ROE, observando-se que o tamanho, a idade e o setor de serviços possuem uma relação positiva e o endividamento possui uma relação negativa, sendo que tal resultado (relação ROE e endividamento) já se verificara na Correlação de Pearson.

Esse resultado comprova que a percepção dos stakeholders não se reflete no desempenho empresarial operacional, corroborando os achados de Domingos e Moura (2013), que não encontraram associação entre tais variáveis. Assim, rejeita-se a hipótese $\mathrm{H}_{1 \mathrm{a}}$.

Quanto ao segundo modelo, que possui como variável dependente o desempenho de mercado (MVA), nota-se significância de até $1 \%$ e um $\mathrm{R}^{2}$ de $48,5 \%$. A reputação corporativa negativa (REP) apresentou uma relação negativa e significante com o MVA. Destarte, a reputação corporativa negativa é um fator que influencia o desempenho empresarial quando considerada a amostra analisada. Diferente do resultado encontrado no primeiro modelo, apenas o endividamento e o setor de serviços apresentaram relação significante, sendo uma relação positiva e outra negativa, respectivamente.

Esse achado indica que a percepção dos stakeholders se reflete no desempenho de mercado, confirmando a definição do MVA $^{\circledR}$ de Young e O’Byrne (2003), segundo a qual o MVA se baseia no comportamento ou percepção do mercado. Assim, o mercado percebe a reputação negativa da empresa, e tal percepção é refletida em desempenho inferior. Esses resultados corroboram os achados de Roberts e Dowling (2002), Thomaz e Brito (2010), Cardoso et al. (2013), Hall Jr. e Lee (2014) e Kakkar e Kaur (2014), que encontraram relação entre reputação corporativa e desempenho empresarial, ainda que seus estudos procurassem relação entre boa reputação corporativa e desempenho. Desse modo, não se rejeita a hipótese $\mathrm{H}_{1 b}$, pois esse resultado confirma que a reputação é tanto um ativo como um construto que surge da percepção e avaliação dos stakeholders, sendo, portanto, um recurso estratégico formado pela opinião, confirmando as perspectivas teóricas adotadas no estudo da Visão Baseada em Recursos e das expectativas sociais.

Como assevera Artoni (2008) e Cardoso et al. (2013), a reputação advém do relacionamento da empresa com os stakeholders, e o desempenho empresarial depende de tal relação. Como demonstrado no estudo, a reputação corporativa negativa tem consequência para o desempenho empresarial - medido pela perspectiva de mercado (MVA) -, em que quanto maior a reputação corporativa negativa menor o seu desempenho, diminuindo sua competitividade e comprometendo sua sobrevivência em um ambiente econômico de competição acirrada. 


\section{CONSIDERAÇÕES FINAIS}

A pesquisa teve por objetivo analisar a relação entre a reputação corporativa negativa e o desempenho empresarial das empresas listadas da BM\&FBovespa. A variável reputação corporativa negativa foi construída a partir do conjunto de ações judiciais trabalhistas e cíveis obtidos por meio da análise de conteúdo das notas explicativas às demonstrações financeiras, assim como pelas reclamações registradas junto ao Sindec no triênio 2009-2011. Já para o desempenho empresarial, foram utilizados o ROE (desempenho operacional) e o MVA (desempenho de mercado), com os dados do exercício de 2012.

Inicialmente, evidenciou-se que aproximadamente $92 \%$ das empresas da amostra possuem capital de origem nacional e controle acionário privado, sendo distribuídas, principalmente entre os setores Financeiro e Outros, Construção e Transporte, Utilidade Pública, Consumo Cíclico e Consumo Não Cíclico. Posteriormente, através da analise descritiva dos dados, foi demonstrado que as empresas da amostra obtiveram em média uma reputação corporativa de 165,70 pontos, sendo que a reputação máxima foi de $3.682,39$ pontos e a mínima de aproximadamente 0 ponto. Para o desempenho empresarial, o MVA possui uma média de 1,43, enquanto o valor máximo é de 56,13 , e o mínimo é de $-23,75$. Já o ROE possui uma média de - 0,14, enquanto o valor máximo é de 13,98, e o mínimo é de - 56,11.

Por meio da reputação corporativa negativa, calculada para o triênio 2009-2011, foram construídos dois rankings, que classificam as dez empresas com maior reputação corporativa negativa e as dez com menor reputação corporativa negativa. Observou-se que prevalecem as empresas de capital nacional nos rankings e de controle privado, no entanto, quando observado o ranking das empresas com menor reputação corporativa. Em relação aos setores, no primeiro ranking, ou seja, das empresas com maior reputação corporativa negativa, notouse que há uma maior concentração de empresas no setor Consumo Cíclico; contudo, quanto ao segundo ranking, não houve prevalência de setores específicos.

Os resultados apresentados apontam que a percepção dos stakeholders não se reflete no desempenho empresarial operacional (ROE), uma vez que não foi encontrada relação significante entre a reputação corporativa negativa e o ROE. Todavia, verificou-se uma relação positiva entre a reputação corporativa negativa e o desempenho empresarial de mercado (MVA). Assim, a percepção dos stakeholders se reflete no desempenho de mercado; logo, o mercado percebe a reputação negativa da empresa, e tal percepção é refletida também em um menor desempenho. Desse modo, a reputação corporativa demonstra ser um recurso estratégico valioso e que surge a partir das expectativas sociais, sendo que, quando é bem gerenciada, tem a capacidade de gerar resultado superior e diferencial competitivo para as organizações. De maneira análoga, se a reputação corporativa é mal gerenciada e construída a partir de más percepções dos stakeholders, as organizações podem ter seu desempenho empresarial comprometido, nesse caso, comprovado pelo desempenho de mercado das empresas da amostra, medido pelo MVA.

Destaca-se a importância dos achados deste estudo, na medida em que se permite concluir que as organizações devem considerar, em suas decisões estratégicas, ações direcionadas para o gerenciamento da reputação corporativa, para avaliar a percepção dos stakeholders, já que a reputação corporativa influencia o desempenho empresarial de mercado, fator preponderante para a continuidade da empresa.

Como limitações deste estudo, destaca-se o período de análise, limitado a três anos para a construção da reputação corporativa negativa, e a um ano para o desempenho empresarial, além dos fatores utilizados para construir a reputação negativa das empresas e dos testes estatísticos empregados. Assim, sugere-se, para estudos futuros, a ampliação do espaço temporal, a inserção de outros itens que considerem a percepção dos stakeholders na elaboração da reputação corporativa negativa, como questões ambientais e tributárias, e, por fim, a utilização de testes estatísticos mais robustos.

\section{REFERÊNCIAS}

ALMEIDA, A. L. C. Reputação organizacional: a importância de parâmetros para seu gerenciamento. Organicom - Revista Brasileira de Comunicação Social e Relações Públicas, v. 2, n. 2, p. 119-133, 2005.

ARTONI, L. F. Reputação corporativa e desempenho: uma analise do contexto brasileiro. 96 f. 2008. Dissertação (Mestrado em Administração) - Centro de Ciências Sociais Aplicadas, Universidade Presbiteriana 
Mackenzie, São Paulo, 2008.

ASSAF NETO, A. A dinâmica das decisões financeiras. Caderno de Estudos, n. 16, p. 1-17, 1997.

BARNETT, M. L.; JERMIER, J. M.; LAFFERTY, B. A. Corporate reputation: the definitional landscape. Corporate Reputation Review, v. 9, n. 1, p. 26-38, 2006.

BARNETT, M. L.; POLLOCK, T. G. The Oxford handbook of corporate reputation. Oxford: Oxford University Press, 2012.

BARNEY, J. Firm resources and sustained competitive advantage. Journal of Management, v. 17, n. 1, p. 99-120, 1991.

BASSO, L. F. C.; KRAUTER, E. Participação nos luscros/resultados e criação de valor: um estudo exploratório. Organização \& Sociedade, v. 10, n. 26, p. 157-178, 2003.

BERGH, D. D.; KETCHEN, D. J.; BOYD, B. K.; BERGH, J. New frontiers of the reputation - performance relationship: insights from multiple theories. Journal of Management, v. 36, n. 3, p. 620-632, 2010.

BRASIL. Ministério da Justiça. Secretaria Nacional do Consumidor. Sistema Nacional de Informação de Defesa do Consumidor. Cadastro nacional de reclamações fundamentais. Disponível em: <http://portal.mj.gov.br/ main.asp? View $=\{19 F 5 F 305-9 E 48-4947-95 F 3-F 6 F A 395170 B A\}>$. Acesso em: 12 mai. 2014.

BRITO, E. Reputação e desempenho: uma análise empírica no setor bancário. Revista Economia e Gestão, v. 5, n. 11, p. 117-142, 2005.

CAIXETA, C. G. F. Competitividade brasileira: um estudo da reputação de empresas nacionais por meio das dimensões governança, desempenho e produtos e serviços. 128 f. 2008. Dissertação (Mestrado em Administração) - Pontifícia Universidade Católica de Minas Gerais, Belo Horizonte, 2008.

CAIXETA, C. G. F.; LOPES, H. E. G.; BERNARDES, P.; CARDOSO, M. B. R.; NETO, A. M. C. Reputação corporativa e desempenho econômico-financeiro: um estudo em cinco grandes grupos empresariais brasileiros. Revista Eletrônica de Gestão Organizacional, v. 9, n. 1, p. 86-109, 2011.

CARDOSO, V. I. C.; DE LUCA, M. M. M.; LIMA, G. A. S. F.; VASCONCELOS, A. C. Reputação corporativa nas empresas brasileiras: uma questão relevante para o desempenho empresarial? Revista Contemporânea de Contabilidade - RCC, v. 10, n. 21, p. 115-136, 2013.

CARVALHO, F. M.; KAYO, E. K.; MARTIN, D. M. L. Tangibilidade e intangibilidade na determinação do desempenho persistente de firmas brasileiras. Revista de Administração Contemporânea, v. 14, n. 5, p. 871$889,2010$.

CASTRO, D. J. Como se constrói uma "reputação corporativa”? 167 f. 2008. Dissertação (Mestrado em Administração) - Escola de Administração, Fundação Getúlio Vargas, São Paulo, 2008.

CERQUEIRA, J. E. A.; SOARES, T. M.; DAVID, M. V. Novas evidências sobre a relação entre a geração de

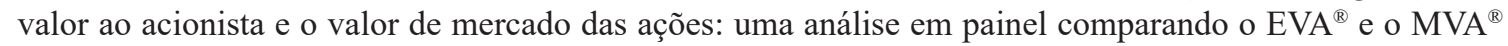
no mercado brasileiro. Revista Pesquisa Operacional para o Desenvolvimento, v. 1, n. 2, p. 178-196, 2009.

COLLIS, J.; HUSSEY, R. Pesquisa em administração: um guia prático para os alunos de graduação e pósgraduação. 2. ed. Porto Alegre: Bookman, 2005.

DOMINGOS, S. R. M.; MOURA, A. A. F. Reputação corporativa e desempenho: uma análise nas maiores companhias abertas do Brasil. In: CONGRESSO USP DE CONTROLADORIA E CONTABILIDADE, 13. 2013, São Paulo. Anais... São Paulo: FEA-USP, 2013.

DOWLING, G. R. Managing your corporate images. Industrial Marketing Management, v. 15, p. 109-115, 1986.

FÁVERO, L. P.; BELFIORE, P.; SILVA, F. L.; CHAN, B. L. Análise de dados: modelagem multivariada para a tomada de decisões. Rio de Janeiro: Campus, 2009.

FOMBRUN, C. J.; SHANLEY, M. What's in a name? Reputation building and corporate strategy. Academy of Management Journal, Mississipi, v. 33, n. 2, p. 233-258, 1990.

FOMBRUN, C. J.; GARDBERG, N. A.; SEVER, J. M. The reputation quotient ${ }^{\mathrm{SM}}$ : a multi-stakeholder measure of corporate reputation. Journal of Brand Management, v. 7, n. 4, p. 241-255, 2000.

GARDBERG, N. A.; FOMBRUN, C.J. The global reputation quotient project: first steps towards a crossnationally valid measure of corporate reputation. Corporate Reputation Review, v. 4, n. 4, p. 303-307, 2002. 
HALL JR. E. H.; LEE J. Assessing the impact of firm reputation on performance: an international point of view. International Business Research, v. 7, n. 12, p. 1-13, 2014.

HORIUCHI, W. S. Reputação corporativa: impacto no valor de mercado das companhias das companhias abertas brasileiras. 60 f. 2010. Dissertação (Mestrado em Administração) - Instituto de Ensino e Pesquisa - Insper, São Paulo, 2010.

KAKKAR, D.; KAUR, T. Evaluating a link between corporate reputation and financial performance: a study of India's most respected companies. International Journal of Entrepreneurship \& Business Environment Perspectives, v.s3, n. 2, p. 939-947, 2014.

MACÊDO, J. M. A.; CORDEIRO, J. F.; PEREIRA, L. A. C.; RIBEIRO FILHO, J. F.; TORRES, U. C. L.; LOPES, J. E. G. Responsabilidade social e reputação corporativa: uma investigação sobre a percepção dos stakeholders numa concessionária de energia elétrica nordestina. RCO - Revista de Contabilidade e Organizações, v. 5, n. 11, p. 69-86, 2011.

MARTINS, G. R.; THEÓPHILO, C. R. Metodologia da investigação científica para ciências sociais aplicadas. 2. ed. São Paulo: Atlas, 2009.

MERCO - Monitor Empresarial de Reputación Corporativa. Disponível em: <http://www.mercoinfo.com>. Acesso em: 7 mai. 2014.

MONTARDO, S. P.; CARVALHO, C. S. Questões teórico-metodológicos sobre métricas e reputação corporativa. Revista Alceu, v. 13, n. 25, p. 168-184, 2012.

ROBERTS, P. W.; DOWLING, G. R. Corporate reputation and sustained superior financial performance. Strategic Management Journal, v. 23, n. 12, p. 1.077-1.093, 2002.

SAMPIERI, R. H.; COLLADO, C. F.; LÚCIO, P. B. Metodologia de pesquisa. 3. ed. São Paulo: McGraw Hill, 2013.

THOMAZ, J. C.; BRITO, E. P. Z. Reputação corporativa: construtos formativos e implicações para a gestão. Revista de Administração Contemporânea - RAC, v. 14, n. 2, p. 229-250, 2010.

VANCE, P. S.; ÂNGELO, C. F. Reputação corporativa: uma revisão teórica. Revista de Gestão USP, v. 14, n. 4 p. $93-108,2007$.

YOUNG, S.; O’BYRNE, S. F. EVA e gestão baseada em valor: guia prático para implementação. Porto Alegre: Bookman, 2003. 